\title{
Embracing the science of value in health
}

\author{
Murray Krahn MD MSc, Stirling Bryan PhD, Karen Lee MA, Peter J. Neumann ScD
}

Cite as: CMAJ 2019 July 2;191:E733-6. doi: 10.1503/cmaj.181606

CMAJ Podcasts: author interview at https://soundcloud.com/cmajpodcasts/181606-ana

${ }^{66} \mathbf{R}$ esource stewardship" is recognized as a key social value in Canada's health system. This is enshrined in both legislation ${ }^{1}$ and a variety of reform initiatives. ${ }^{2,3}$ Canadians want a health system that meets their needs, is informed by evidence and fair, but also one that uses Canadian resources wisely. Cost-effectiveness analysis is one way to think rationally about resource allocation. Cost-effectiveness analysis is now used widely in both low- and high-income countries to inform decisions about drugs, vaccines, medical devices and health programs. In Canada, the Canadian Agency for Drugs and Technologies in Health (CADTH) Common Drug Review and the Ontario Health Technology Advisory Committee are examples of groups that use this analysis for decisions about coverage and reimbursement.

Most clinical practice guideline and advisory groups, though, do not use cost-effectiveness analysis. Some consider these analyses to be low-quality evidence. ${ }^{4}$ High-impact general medical journals tend to publish few economic analyses. One reason, perhaps, is that cost-effectiveness is not considered to be reliable or scientific by journal editors and guideline developers trained in epidemiologic methods. Randomized controlled trials are often considered to be the highest form of evidence, because the findings of a well-conducted trial are assumed to be reliable and tell us something "true" about the world. Cost-effectiveness analysis, on the other hand, has a lingering reputation of being an unscientific technique for integrating data of varying quality and dubious provenance, having once been described as building "aerial palaces of decision analysis" amidst the "haze of Bayes. ${ }^{n}$ But is this still justified?

Canada spends more than one-tenth of its national wealth on health care and the United States spends nearly a fifth. ${ }^{6}$ Advances in science and technology, an aging population, thirdparty payment and increasing medical specialization are driving costs upward. We need a way to make rational decisions about costs in relation to benefits to patients and society. We argue that cost-effectiveness analysis is in fact scientific. It is the science of value in health, a valuable tool for integrating evidence about resource use into health decision-making. We discuss how cost-effectiveness analysis can inform decisions in a world where patients demand access to promising drugs, physicians demand to use the latest technology, the private sector demands support for innovation, and even the public sector hopes to use health spending to drive economic growth.

\section{KEY POINTS}

- Resource stewardship is recognized as an important goal within our health systems.

- Cost-effectiveness analysis is an important tool supporting wise use of resources, but its application has been limited, in part, by the perception that it is unscientific.

- In recent years, methodologic advances in evidence synthesis, use of population-level administrative data, preference measurement, validation and calibration have strengthened the scientific foundation of cost-effectiveness analysis.

- Cost-effectiveness analysis should, as the science of value in health, be more widely adopted in health decision-making not only in decisions around reimbursement but also in clinical guideline development and public health decision-making.

\section{Cost-effectiveness analysis: scientific origins and purpose}

Cost-effectiveness analysis represents the confluence of several streams of inquiry: economic theory, engineering, operations research $^{7}$ and, arguably, epidemiology. Because each of these is either a type of social science (e.g., economics) or applied science (e.g., engineering, operations research), costeffectiveness may also be thought of as a hybrid applied science, by which we mean "the use of scientific processes and knowledge as the means to achieve a particular practical or useful result." ${ }^{8}$

Such analyses typically integrate health data of different types: epidemiologic data for natural history of disease, data from trials or observational studies for effectiveness, preference (utility) data for health outcomes and cost data from various sources. They may employ one of several types of decision model, such as decision trees, state-transition models, compartment- or agent-based models, or may use primary data from administrative databases or trials to represent complex biological or systems phenomena. Data are combined in a common analytic framework, and a summary statistic such as the incremental cost-effectiveness ratio, or net health benefit, is generated. These are measures of efficiency that represent the relation between additional resource use and additional health benefit. The statistic can be interpreted as a tool for maximizing health (an 
extra-welfarist perspective), improving overall societal wellbeing (a welfarist perspective) or simply providing support to decision-makers (a social decision-making perspective). ${ }^{9}$

\section{Do we need a science of value?}

Consider the following example of an organization deliberately avoiding the question of the value of cancer treatments. In 2010, the Cameron government in the United Kingdom established the Cancer Drugs Fund to provide access to cancer drugs that were not available through the National Health Service. In the midst of intense political pressure from patients with cancer, the government proposed to expand access to cancer drugs, most of which had been rejected by the National Institute for Health and Care Excellence (www.nice.org.uk) because these drugs did not meeting cost-effectiveness criteria. The initial budget of 50 million pounds grew rapidly to 340 million pounds. Following a 3-month evaluation period in 2016, the Cancer Drugs Fund's mandate was changed. It became closely aligned with the National Institute for Health and Care Excellence, and drugs that had previously been rejected by the institute were no longer funded.

A 2017 review found that there was no evidence that the Cancer Drugs Fund delivered meaningful value to patients of the National Health Service. ${ }^{10}$ The fund spent 1.2 billion pounds, with estimated potential gains of 3500 quality-adjusted lifeyears (QALYs) offset by the potential loss of 18000 QALYs (600900 lives) associated with potential alternative uses of the money.

\section{What are some common criticisms of cost- effectiveness analysis?}

\section{It is a black box}

In addition to the construction of a model, the selection of data and analytic method are subject to the analyst's judgment. The complexity and potential variability of this process has led to concerns that cost-effectiveness modelling is a "black box," with results that nonexperts are expected to accept on faith. ${ }^{11}$ This relates to concerns about the potential for bias, particularly when the analysis is conducted by or for a stakeholder with a strong financial incentive. ${ }^{12}$

\section{Garbage in, garbage out}

The early days of meta-analysis were characterized by anguished hand-wringing about the legitimacy of combining "apples and oranges."13 By comparison, cost-effectiveness also combines grapes, bananas, kiwis and the odd durian.

\section{The ethical underpinnings are dubious}

The QALY, which is the standardized unit of health most commonly used in cost-effectiveness analysis, assigns every year of full health in every person the same weight. Usually, although not invariably, the analysis places an equal weight on health gains in those who are sick, healthy, poor and wealthy. ${ }^{14}$ These ethical implications are not universally accepted.

\section{Is cost-effectiveness becoming more robust?}

Yes, we think it is.

In 2016, the US Second Panel on Cost Effectiveness in Health and Medicine published its update of the 1996 guidelines for cost-effectiveness analysis. ${ }^{15}$ In 2017, CADTH published the 4th version of the Canadian guidelines for the economic evaluation of health technologies. ${ }^{16}$ These were signal events in the halfcentury history of the discipline and reflect the growing scientific consensus around best methods.

\section{Reference case}

Perhaps the most important advance has been the idea of the reference case. In the early years, published cost-effectiveness analyses used different perspectives, sources of preferences, discount rates and time horizons. The idea of the reference case is that analyses should be conducted with similar methods to facilitate consistency and allow comparisons. Canadian reference case analyses should be conducted from the perspective of the public payer, use a lifetime time horizon in the presence of mortality benefit, use community-weighted preferences, and discount future costs and health effects at $1.5 \%$ per annum. Use of the reference case enhances the value of the analysis through consistency, even if the consensus on methods is not complete.

\section{Better empirical data}

Advanced methods for evidence synthesis (e.g., network metaanalysis) are being used increasingly to estimate relative effectiveness in cost-effectiveness analyses. Large-scale, populationderived administrative data are also being used increasingly to estimate patterns of care, adverse effects and longitudinal costs. ${ }^{17}$ Because most provinces now have records of every interaction with the health system, it is possible to estimate the actual costs borne by these health systems. In addition, increasing international experience with community-weighted-preference sets has increased the reliability of preference data. ${ }^{18}$

\section{A standardized unit of health}

Broad consensus around the use of health-adjusted life-years (e.g., the QALY) as measures of health for cost-effectiveness analysis might equal the adoption of the reference case in importance. The value of having standardized units of health cannot be overstated. Being able to say what is large and what is small across every disease, intervention and setting is an extraordinary advance.

\section{Analytical methods}

Analytical methods have seen rapid development over the past 30 years. Groups of researchers have been funded for multiinstitution, multiyear efforts to refine and validate policy models (or whole-disease models) that can be used for multiple applications within a single disease. The Cancer Intervention and Surveillance Modelling Network collaboration and the Mount Hood Challenge are 2 such efforts. ${ }^{19,20}$ Sophisticated methods of handling heterogeneity and uncertainty regarding 
estimates of epidemiologic, cost and utility have been developed. Models are now routinely validated against external data, and methods for calibration for unknown model parameters continue to be developed.

\section{Empirical estimation of the cost-effectiveness threshold}

Finally, researchers in the UK, Europe and Australia have provided empirical estimates of the cost-effectiveness threshold by estimating the relation between changes in health expenditure and changes in health. ${ }^{21}$

\section{Challenges for the future}

Improving model sharing, enhancing transparency and other challenges to methods of analysis remain. ${ }^{22}$ Perhaps the greatest need is in the area of application. Is cost-effectiveness analysis useful for micro (individual patients), meso (classes of patients) or macro (policy level) decision-making?

Our view is that cost-effectiveness analysis is likely to be most useful at meso and macro levels of decision-making and less useful at the individual level. At the meso level, clinical practice guidelines in many jurisdictions do not include considerations of cost-effectiveness at present. The guideline movement is slowly evolving in the direction of including broader classes of evidence, ${ }^{23,24}$ but more progress is needed. At the macro level, a particular need is within public health. Vaccines and other public health interventions in many jurisdictions are often not evaluated for cost-effectiveness.

A second question is: How should cost-effectiveness analysis be integrated with other factors in decision-making? It is tempting for many health economists to think about cost-effectiveness as the normative solution for decision-making in health. ${ }^{25}$ In our view, cost-effectiveness analysis cannot play this role. Costeffectiveness does not fully represent the uncertainties inherent in estimates of the benefits and risks of treatment. Equity considerations related to the distribution of health gains, and broader questions of social value, autonomy, dignity, preferences for treatments and processes, legal, religious and cultural considerations, feasibility and institutional priorities are difficult, if not impossible, to incorporate. In Canadian decision-making contexts, these broader questions usually are, and in our view should be, addressed by other methods..$^{26,27}$

The scientific (and policy) challenge for the near future will be in broadening the reach of cost-effectiveness analysis across countries and settings, and integrating the science of value into health decisions in a way that respects not only system-level fiscal challenges but also the full range of factors that are relevant to health decisions: clinical evidence, patient preferences, social values and system feasibility.

\section{Conclusion}

Cost-effectiveness analysis has matured to the point where it should routinely inform reimbursement, coverage and disinvestment decisions, in both clinical and public health settings. Canadians should expect guidelines for clinical practice and public health policy to be routinely informed by cost-effectiveness analyses.

\section{References}

1. Bill 46, Excellent Care for All Act, 2010. Legislative Assembly of Ontario. Available: www.ontla.on.ca/web/bills/bills_detail.do?locale=en\&Intranet=\&BillıD =2326 (accessed 2014 Feb. 6).

2. Giacomini M, Wagner F, Krahn M, et al. Social and ethical values for health technology assessment in Ontario. In: Health quality transformation. Toronto: Health Quality Ontario; 2012.

3. Commission on the Future of Health Care in Canada: The Romanow Commis sion. Ottawa: Health Canada; 2009. Available: www.canada.ca/en/health-canada /services/health-care-system/commissions-inquiries/federal-commissions-health -care/commission-future-health-care-canada-romanow-commission.html (accessed 2019 May 30).

4. Haines A, Wong WW, Krahn M. Canadian hepatitis C virus screening guideline: a disconnect between evidence and recommendations. CMAJ 2017;189:E1150.

5. Feinstein AR. Clinical biostatistics. XXXIX. The haze of Bayes, the aerial palaces of decision analysis, and the computerized Ouija board. Clin Pharmacol Ther 1977;21:482-96.

6. Papanicolas I, Woskie LR, Jha AK. Health care spending in the United States and other high-income countries. JAMA 2018;319:1024-39.

7. Quade ES. A history of cost-effectiveness. Santa Monica (CA): The Rand Corporation; 1994. Available: www.dtic.mil/dtic/tr/fulltext/u2/730430.pdf (accessed 2018 Apr. 13).

8. Roll-Hansen N. Why the distinction between basic (theoretical) and applied (practical) research is important in the politics of science. London (UK): Centre for the Philosophy of Natural and Social Science Contingency and Dissent in Science; 2009. Available: https://pdfs.semanticscholar.org/62f0/dced123c24c 7bc89b7d0d72bfcf885634a43.pdf (accessed 2018 Apr. 26).

9. Brouwer WBF, Culyer AJ, van Exel NJ, et al. Welfarism vs. extra-welfarism $J$ Health Econ 2008;27:325-38.

10. Aggarwal A, Fojo T, Chamberlain C, et al. Do patient access schemes for highcost cancer drugs deliver value to society? - lessons from the NHS Cancer Drugs Fund. Ann Oncol 2017;28:1738-50.

11. John-Baptiste AA, Bell C. A glimpse into the black box of cost-effectiveness analyses. CMAJ 2011;183:E307-8.

12. Bell CM, Urbach DR, Ray JG, et al. Bias in published cost-effectiveness studies: systematic review. BMJ 2006;332:699-703.

13. Naylor CD. Two cheers for meta-analysis: problems and opportunities in aggregating results of clinical trials. CMAJ 1988;138:891-5.

14. Cookson R, Mirelman AJ, Griffin S, et al. Using cost-effectiveness analysis to address health equity concerns. Value Health 2017;20:206-12.

15. Neumann P, Sanders G, Russell L, et al. Cost-effectiveness in health and medicine. 2nd ed. Oxford (UK): Oxford University Press; 2016.

16. Guidelines for the economic evaluation of health technologies: Canada, 4th edition. Ottawa: Canadian Agency for Drugs and Technologies in Health; 2017. Available: www.cadth.ca/about-cadth/how-we-do-it/methods-and-guidelines/ guidelines-for-the-economic-evaluation-of-health-technologies-canada (accessed 2018 May 23).

17. de Oliveira C, Bremner KE, Pataky R, et al. Understanding the costs of cancer care before and after diagnosis for the 21 most common cancers in Ontario: a population-based descriptive study. CMAJ Open 2013;1:E1-8.

18. Xie F, Pullenayegum E, Gaebel K, et al. A time trade-off-derived value set of the EQ-5D-5L for Canada. Med Care 2016;54:98-105.

19. Alagoz O, Berry DA, de Koning HJ, et al. Introduction to the Cancer Intervention and Surveillance Modeling Network (CISNET) breast cancer models. Med Decis Making 2018;38(Suppl 1):3S-8S.

20. Palmer AJ, Mount Hood 5 Modeling Group, Clarke P, Gray A, et al. Computer modeling of diabetes and its complications: a report on the Fifth Mount Hood Challenge meeting. Value Health 2013;16:670-85.

21. Claxton K, Martin S, Soares M, et al. Methods for the estimation of the National Institute for Care and Excellence cost-effectiveness threshold. Health Technol Assess 2015;19:1-503.

22. Neumann PJ, Kim DD, Trikalinos TA, et al. Future directions for cost-effectiveness analyses in health and medicine. Med Decis Making 2018;38:767-77. 
23. Krahn M, Naglie G. The next step in guideline development: incorporating patient preferences. JAMA 2008;300:436-8.

24. Garrison LP. Cost-effectiveness and clinical practice guidelines: Have we reached a tipping point? - an overview. Value Health 2016;19:512-5.

25. Claxton K, Sculpher M, Drummond M. A rational framework for decision making by the National Institute for Clinical Excellence (NICE). Lancet 2002;360: 711-5.

Competing interests: Peter Neumann received no funding for the submitted work. He has received research grants from Amgen, Lundbeck, the Bill \& Melinda Gates Foundation, NPC, the Alzheimer's Association, National Institutes of Health and the Pharmaceutical Research and Manufacturers of America for activities outside of the submitted work. He has also received financial support from AveXis as a member of the Forum for Gene Therapy Health Economics Group for research into the evaluation of gene therapies; one-time compensation as a member of the advisory boards of Bayer, Novo Nordisk, Amgen, Veritech, Sage, Sarepta Therapeutics, Biogen, Merck, DePuy Synthes, GlaxoSmithKline, Otsuka Pharmaceutical, ICON and Indivior; consultant fees from Vertex, Precision Health Economics, GlaxoSmithKline and Research Triangle Institute; and lecture or speaker fees from Celgene, Roche and Research Triangle Institute. No other competing interests were declared.

This article has been peer reviewed.
26. Krahn M, Miller F, Bayoumi A, et al. Development of the Ontario Decision Framework: a values-based framework for health technology assessment. Int J Technol Assess Health Care 2018;34:290-9.

27. Guindo LA, Wagner M, Baltussen R, et al. From efficacy to equity: literature review of decision criteria for resource allocation and healthcare decisionmaking. Cost Eff Resour Alloc 2012;10:9.

Affiliations: Toronto Health Economics and Technology Assessment Collaborative (Krahn); Toronto General Hospital Research Institute (Krahn), Toronto, Toronto, Ont.; BC SUPPORT Unit (Bryan), BC Academic Health Science Network, Vancouver, BC; School of Population and Public Health (Bryan), University of British Columbia; Centre for Clinical Epidemiology \& Evaluation (Bryan), Vancouver Coastal Health Research Institute, Vancouver, BC; Canadian Agency for Drugs and Technologies in Health (Lee); School of Epidemiology and Public Health (Lee), University of Ottawa, Ottawa, Ont.; Center for the Evaluation of Value and Risk in Health (Neumann), Institute for Clinical Research and Health Policy Studies, Tufts Medical Center, Boston, Mass.

Contributors: All of the authors made substantial contributions to the conception and design of the work, revised it critically for important intellectual content, gave final approval of the version to be published and agreed to be accountable for all aspects of the work.

Correspondence to: Murray Krahn, murray.krahn@theta.utoronto.ca 